\title{
PENERAPAN TEKNOLOGI PROSES PANEN MODERN TERHADAP KESEJAHTERAAN WARGA DESA JAYANEGARA KECAMATAN TEMPURAN
}

\author{
${ }^{1}$ Murtalim, Viqry ${ }^{2}$ Andriansyah, ${ }^{3}$ Zulfikri Abdur Rahman, ${ }^{4}$ Ria Fajriah, \\ ${ }^{5}$ Elsa Tiara Novanti, ${ }^{6}$ Aris Munandar, ${ }^{7}$ Ida Permatasari, ${ }^{8}$ Komarudin, \\ ${ }^{9}$ Eka Falah Ramadhan, ${ }^{10}$ Lidya Nur'aeni, ${ }^{11}$ Betty Ayu Rahmaditiya, \\ ${ }^{12}$ Candra Triatna, ${ }^{13}$ Hanna Mutia Trisindo

\section{${ }^{1}$ Teknik Mesin, ${ }^{11-12}$ Teknik Informatika, ${ }^{6-7}$ Manajemen, ${ }^{10}$ Hukum, ${ }^{8-9}$ A kuntansi, ${ }^{4}$ Farmasi, ${ }^{3}$ Teknik Industri, ${ }^{5}$ Psikologi, ${ }^{2}$ Sistem Informasi, 13 PGSD}

Fakultas Teknik dan Ilmu Komputer, UBP Karawang

Jl. HS.Ronggo Waluyo, Telukjambe Timur, Karawang, Jawa Barat 41361

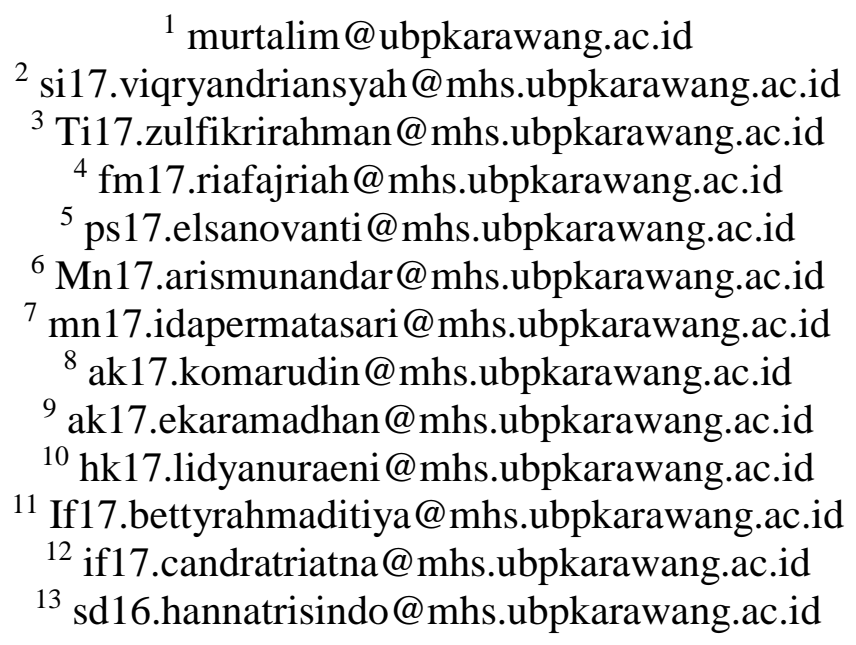

\begin{abstract}
ABSTRAK
Desa Jayanegara adalah sebuah desa yang terletak di Kecamatan Tempuran Kabupaten Karawang dengan sebagian besar mata pencaharian penduduknya mengandalkan dari sektor pertanian terutama padi sawah, Dalam pemanenannya petani padi menggunakan alat-alat pertanian yang bersifat mekanis atau menggunakan tenaga mesin menjadi suatu teknologi alternatif dalam meningkatkan effsiensi dan efektifitas produksi hasil pertaniannya. Penelitian ini bertujuan untuk mecari permasalahan dan solusi terkait potensi peningkatan kesejahteraan para petani dalam meningkatkan hasil panen. Metode yang digunakan dalam penelitian ini yaitu dengan menggunakan analisis SWOT. Analisis SWOT bertujuan untuk mengetahui kekuatan dan kelemahan serta kesmpatan dan ancaman yang dimiliki desa. Hasil dari penelitian ini menunjukkan penurunan hasil panen dan tingkat kesejahteraan pada masyarakat yang diakibatkan kurangnya penanganan teknologi proses panen pertanian di desa Jayanegara.
\end{abstract}

Kata Kunci : mesin pertanian, jayanegara, kesejahteraan 


\begin{abstract}
Jayanegara Village is a village located in Tempuran Subdistrict, Karawang Regency with most of the livelihoods of the population relying on the agricultural sector, especially lowland rice. In harvesting rice farmers use mechanical agricultural tools or use mechanical power to become an alternative technology in increasing efficiency and the effectiveness of agricultural production. This study aims to find problems and solutions related to the potential for increasing the welfare of farmers by increasing crop yields. The method used in this research is by using a SWOT analysis. The SWOT analysis aims to determine the strengths and weaknesses as well as the opportunities and threats that the village has. The results of this study indicate a decline in the economy in the community due to the lack of handling of agricultural harvest technology in the village of Jayanegara.
\end{abstract}

Keywords : agricultural machinery, jayanegara, welfare

\title{
PENDAHULUAN
}

Pendampingan masyarakat dapat definisikan sebagai suatu bentuk hubungan antara kelompok masyarakat dan pendamping yang bertujuan menghadapi tantangan dalam berbagai aspek seperti: Ekonomi masyarakat sarana dan prasarana, kesehatan, tingkat pendidikan masyarakat, sosial dan budaya (Qmariah, 2016). Peran yang dimiliki pendampingan sosial sangat menentukan keberhasilan program pemberdayaan masyarakat. Pentingnya partisipasi publik dalam pemberdayaan masyarakat sangat perlu diperhatikan sesuai dengan prinsip pemberdayaan. Dalam hal ini, peranan seorang pekerja sosial atau pendamping masyarakat bukan sebagai penyembuh atau pemecah masalah secara langsung, akan tetapi seringkali diwujudkan dalam kapasitasnya sebagai pendamping. Pendamping biasanya membantu membangun dan memperkuat jaringan dan relasi antara komunitas setempat dan kebijakan-kebijakan pembangunan yang lebih luas.

Upaya pemberdayaan masyarakat desa dibutuhkan pendampingan dari pihak lembaga yang berkompeten dalam urusan pemberdayaan masyarakat.

Perguruan tinggi adalah salah satu lembaga yang mampu memberikan pendampingan kepada masyarakat desa. Salah satu program Tri Dharma Perguruan tinggi ialah pengabdian kepada masyarakat. Umumnya permasalahan yang timbul di masyarakat desa identik dengan pendidikan yang masih rendah, pendapatan yang 
rendah, produktivitas yang masih rendah, perkawinan muda. Dengan kenyataan ini, tujuan pengabdian pada masyarakat diharapkan dapat membantu menyelesaikan permasalahan tersebut.

Desa Jayanegara merupakan desa yang terletak di utara karawang, termasuk kedalam kecamatan Tempuran kab. Karawang. Desa tersebut memiliki wilayah pemukiman yang cukup sedikit dibandingkan dengan luas wilayah pesawahan dan juga desa tersebut masuk kedalam kategori desa swadaya dengan luas wilayah 485 hektar. Bila dilihat dari sumber daya alam yang ada, desa jayanegara memiliki potensi ekonomi yang cukup dari sektor pertanian. Namun, kenyataannya belum dioptimalkan dikarenaan beberapa faktor diantaranya sumber daya manusia, pendidika, dan lain-lain. Tujuan diadakannya kegiatan pengabdian masyarakat ini adalah untuk mendampingi masyarakat dalam mencapai tujuannya dalam hal pembangunan desa secara berkesinambungan.

\section{METODE}

\section{Program Kegiatan}

Kegiatan ini di fokuskan pada identifikasi permasalah yang terjadi pada saat proses penanganan hasil panen dilingkungan masyarakat desa Jayanegara kemudian lakukan analisis dan menemukan solusi atas permaslaahan yang ada.

\section{Analisa Kebutuhan Program}

Dalam kegiatan ini dibutuhkan data-data lapangan yang terkait dengan hasil pemakaian alat panen modern di lokasi sawah desa jayanegara

\section{Model atau Pendekatan}

Untuk memperoleh data pada penelitian ini dilakukan pendekatan secara langsung melalui wawancara dengan para petani setempat

\section{Peserta yang Terlibat}

Peserta yang terlibat pada pengabdian masyarakat ini terdiri dari Dosen pembimbing lapangan (DPL) dan Mahasiswa. 


\section{Penyelesaian Masalah}

Penyelesaian maslah dilakukan dengan cara mengidentifikasi permasalahan yang ada didesa Jayanegara dengan analisis SWOT. Tujuannya untuk mengetahui kelebihan dan kekurangan, serta peluang dan acaman akibat penggunaan alat mesin pertanian modern.

\section{Hasil yang diharapkan}

Hasil yang diharapkan dengan adanya kegiatan pengabdian masyarakat ini adalah dapat membantu dalam peningkatan kesejahteraan petani dan warga desa.

\section{HASIL DAN PEMBAHASAN}

Analisis SWOT digunakan untuk mencari solusi yang tepat bagi permasalahan yang ada. Strategi dan solusi atas permasalahan yang mengacu pada kelemahan dan ancaman Desa Dongkal yang disesuaikan dengan kekuatan dan kesempatan yang ada tersebut dirumuskan sebagai berikut ini:

\section{Tabel 1 Matrik SWOT}

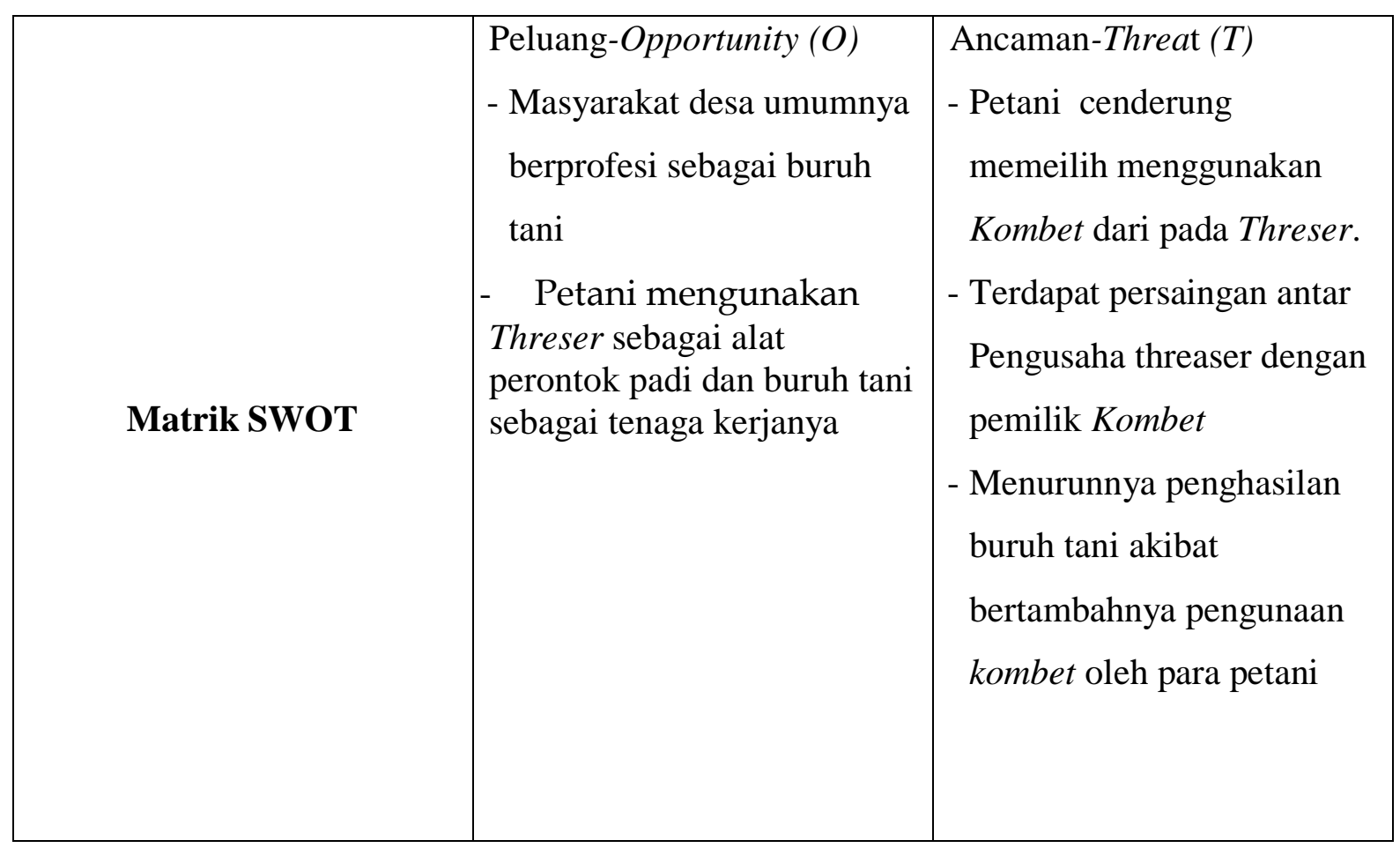




\begin{tabular}{|c|c|c|}
\hline $\begin{array}{l}\text { Kekuatan-Strength }(S) \\
\text { - Terdapata peningkatan } \\
\text { produktifitas hasil panen } \\
\text { petani yang menggunakan } \\
\text { Combine harvester } \\
\text { - Terdapat pengurangan } \\
\text { waktu penanganan hasil } \\
\text { panen } \\
\text { - Terdapat penurunan biaya } \\
\text { operasional pengambilan } \\
\text { hasil panen }\end{array}$ & $\begin{array}{l}\qquad \text { (S 1,2- O 1,2) } \\
\text { Pemerintah daerah setempat } \\
\text { mengadakan pelatihan untuk } \\
\text { meningkatkan skill SDM } \\
\text { terkait teknologi dan } \\
\text { informasi pengolahan } \\
\text { sumber daya. }\end{array}$ & $\begin{array}{l}\text { (S 1,2- T 1,2) } \\
\text { Pemerintah Memberikan } \\
\text { bantuan alat mesin pertanian } \\
\text { Combine harvester untuk } \\
\text { kelompok tani }\end{array}$ \\
\hline $\begin{array}{l}\text { Kelemahan-Weakness }(w) \\
\text { - Kemapuan SDM yang } \\
\text { masih rendah dan } \\
\text { banyaknya pengangguran } \\
\text { - Rendahnya penghasilan } \\
\text { warga buruh tani }\end{array}$ & $\begin{array}{l}\quad \text { (W 1,2- O 1,2) } \\
\text { - Peningkatan standar } \\
\text { pendidikan Desa untuk } \\
\text { meningkatkan taraf } \\
\text { kesejahteraan kehidupan. } \\
\text { - Penanaman sebagian lahan } \\
\text { sawah untuk berkebun } \\
\text { (menanam palawija/ } \\
\text { sayura-sayuran) }\end{array}$ & $\begin{array}{l}\quad \text { (W 1,2- T 1) } \\
\text { - Melakukan pelatihan } \\
\text { teknologi tepat guna agar } \\
\text { bisa menciptakan lapangan } \\
\text { kerja baru } \\
\text { - Petani secara bijak agar } \\
\text { sebagaian lahan panennya } \\
\text { yang menggunakan alat } \\
\text { threser }\end{array}$ \\
\hline
\end{tabular}

Smber: Pengolahan data, 2020

\section{Pengembangan Potensi Desa}

- Potensi ekonomi di Desa Jayanegara yaitu dari bidang pertanian karena hampir $70 \%$ lahan desa yaitu pesawahan sehingga jika dikembangkan menjadi perkebunan yang berpotensi tinggi untuk mendorong perekonomian masyarakat, Terdapata peningkatan produktifitas hasil panen petani yang menggunakan Combine harvester selain itu terdapat pengurangan waktu penanganan hasil panen dan penurunan biaya operasional pengelolaan hasil panen. 


\section{KESIMPULAN DAN SARAN}

\section{Kesimpulan}

Berdasarkan kegiatan yang telah dilakukan dapat disimpulkan yaitu sebagai berikut:

1. Desa Jayanegara masih termasuk pada desa swadaya

2. Faktor ekonomi dan sumber daya manusia masih rendah

3. Kurangnya pengelolaan teknologi hasil pertanian untuk meningkatkan hasil pertanian.

4. Perlunya dilakukan pelatihan teknologi tepat guna agar bisa menciptakan lapangan kerja baru

5. Petani secara bijak agar sebagaian lahan sawah yang akan dipanen untuk menggunakan alat threser.

\section{DAFTAR PUSTAKA}

Badan Pusat Statistik, 2020. Laju Pertumuhan Penduduk. Diakses 10 Oktober 2020 dari http://www.bps.go.id/indikator/ indikator/view_data_pub/0000/api_ pub/50/da_03/1

Subaktilah, Y., Kuswardani, N., Yuwanti, S. 2018. Alisis SWOT: Faktor Internal dan Eksternal pada Pengembangan Usaha Gula Merah Tebu (Studi Kasus di UKM Bumi Asih, Kabupaten Bondowoso). Jurnal Argoteknologi. 12(02). 107-115.

Suyito, S. \& Sodik, M. A., 2015. Dasar Metodologi Penelitian. Yogyakarta: Literasi Media Publishing.

Ali, Akhwan, 2017, Pengaruh Teknologi Pertanian Terhadap Produktivitas Hasil Panen Padi di Kecamatan Maritengngae Kabupaten Sidenreng Rappang, Jurnal Ilmiah

Iswari, Kasma, 2013, Kesiapan Teknologi Panen Dan Pascapanen Padi Dalam Menekan Kehilangan Hasil Dan Meningkatkan Mutu Beras, Jurnal Ilmiah 
Sulistiaji, Koes, 2007, Buku Alat dan Mesin (alsin) Panen dan Perontokan Padi di Indonesia, Balai Besar Pengembangan Mekanisasi Pertanian, BPPP. 